\title{
0 Fenômeno Semiótico da Tradução em Omar Calabrese: Uma Resenha
}

\author{
The Semiotic Phenomenon of Translation in Omar \\ Calabrese: A Review
}

por Júlia Pelachini Farias e Sandra Regina Ramalho e Oliveira

\section{RESUMO}

Esta resenha tem como objetivo apresentar observações sobre a transposição intersemiótica, denominada tradução, de autoria do semioticista Omar Calabrese. A partir do texto Lo strano caso dell'equivalenza imperfetta (modeste osservazioni sulla traduzione intersemiótica), ou 0 estranho caso da equivalência imperfeita (modestas observações sobre a tradução intersemiótica), inédito em português, tentamos esclarecer proposições sobre a tradução intersemiótica de Calabrese. Evitando o perigo da superficialidade e procurando a fidelidade ao autor, mantivemos a estrutura do texto e os subtítulos das seções. A conclusão é a de que sim, é possível fazer tradução, mas sempre imperfeita, pois os processos não são equivalentes entre si.

Palavras-chaves: tradução, semiótica, Omar Calabrese

\section{ABSTRACT}

This review aims to present observations on the intersemiotic transposition, called translation, by the semiotician Omar Calabrese. From the text Lo strano caso dell'equivalenza imperfetta (modeste osservazioni sulla traduzione intersemiotica), or The Strange Case of imperfect equivalence (modest observations on the inter-semiotic translation), unprecedented in Portuguese, we show propositions about intersemiotic translation by Calabrese. Trying to avoid the danger of superficiality and seeking to be faithful to the author, we kept the structure of the text and even the captions of the sections. The conclusion of the text about translation is that it is indeed possible, but always imperfect, since the processes cannot be equivalent within each other

Keywords: translation, semiotic, Omar Calabrese 


\section{0 fenômeno Semiótico da Tradução em Omar Calabrese: \\ Uma Resenha}

\section{Exórdio}

Este texto consiste na apresentação de postulações do semioticista Omar Calabrese acerca da transposição intersemiótica, denominada por ele tradução e este é o tema principal desta resenha. Sua fonte é um trabalho inédito em português, que abre uma coletânea intitulada, no original, Fra parola e imagine: metodologie ed esempi di analisi (Entre palavra e imagem: metodologias e exemplos de análises), publicada na língua italiana pela Editora Mondadori Universitária de Milano, em 2008. Seu autor, o semioticista italiano Omar Calabrese, desaparecido precocemente em 2012 aos 62 anos de idade, foi uma das maiores autoridades nesse tipo específico de fenômeno linguístico, a tradução intersemiótica.

Base teórica para diversos estudos, as proposições de Calabrese ultrapassam o interesse apenas de semioticistas, pois consistem em um referencial relevante para todos quanto se interessam não exclusivamente por relações intersemióticas, mas pelas linguagens estéticas em particular, do Teatro à Moda, do Design à Música, além das Artes Visuais e outras linguagens sincréticas, dado que Bakhtin (2002, p.75) já nos dizia 0 quanto os purismos linguísticos são ilusórios e mesmo até impossíveis, o que Calabrese reitera, já no início desta escritura.

Lo strano caso dell'equivalenza imperfetta (modeste osservazioni sulla traduzione intersemiótica), ou 0 estranho caso da equivalência imperfeita (modestas observações sobre a tradução intersemiótica) está dividido em doze seções, que iniciam com uma premissa, transita entre dúvidas, retoma autores clássicos e culmina com o que Calabrese denomina de "conclusão antiderridiana". Tentando evitar o perigo da superficialidade e procurando ser fiéis ao autor, mantivemos a estrutura do texto e até mesmo os subtítulos das seções. Assim, a estrutura do texto segue a do autor estudado, configurando-se como fora do usual, uma vez que ainda se acrescenta a ela uma introdução ou exórdio e considerações finais, denominada peroração.

Uma questão de ordem normativa precisa ser colocada. É o fato de que o texto original traz apenas o ano da publicação da obra do autor citado, o que nos impediu de cumprir a norma desta Revista quanto a colocar no texto, além da data, o número da página. Esta premissa foi também seguida por nós ao citar o próprio Calabrese, pois todas as referências referem-se a um único artigo seu; assim, a recorrente repetição de uma data seria inócua.

0 acesso ao pensamento de Omar Calabrese caracteriza-se como uma oportunidade para conferir suas ideias sobre o intertextual, que não se trata de tarefa para iniciantes. Por este motivo, este artigo não se caracteriza como uma tradução e, do mesmo modo, não como uma resenha, pois se de um lado não se apresenta na íntegra, nem compromissado com a fidelidade literária, de outro houve o entendimento de que uma resenha, apenas, não daria conta de uma reflexão em área de estudos que, segundo o próprio autor, não é "muito frequentada em semiótica e nos outros setores das ciências humanas". 


\section{0 fenômeno Semiótico da Tradução em Omar Calabrese: \\ Uma Resenha}

\section{Premissa}

Omar Calabrese inicia seu trabalho dizendo que o objetivo do livro "Entre palavra e imagem: metodologias e exemplos de análises" é questionar o problema geral da tradutibilidade. Acrescenta que nenhum texto é verdadeiramente puro, mas é constituído de um sistema complexo de relações entre modos expressivos diferentes entre si. Lembra que o significado pode ser um só, mesmo que diferentes culturas organizem-no de modos distintos; todo texto, portanto, refere-se a um Plano de Conteúdo da mesma maneira, mas todo texto é construído utilizando o Plano de Expressão de formas variadas, seguindo a natureza da base utilizada. Assim, a premissa de Calabrese é a de que é possível a tradução entre substâncias distintas, aqui entendida como linguagens diferentes. Isto é, para um mesmo Plano de Conteúdo é possível que sejam criados diferentes Planos de Expressão. Ou ainda, um mesmo conteúdo pode ser traduzido para diversos textos, de igual ou distintas substâncias.

\section{A Tradução Intersemiótica}

Embora adote o termo "tradução", Calabrese questiona este uso, pois quando se enfrenta uma transmigração de motivos, temas ou textos inteiros do Plano de Expressão visual ao verbal e vice-versa, não se utiliza o termo tradução. Ele então exemplifica com os possíveis modos de transmigração: para o texto que converte uma imagem em palavras, se usa o termo "descrição"; para a imagem que converte um texto em imagem atribui-se o nome de "ilustração"; e quando de um texto só interessa isolar um dos níveis do percurso gerativo de sentido, como o narrativo, para migrar de uma substância à outra, chamamos de "redução".

Podemos considerar todos estes casos como tradução? ele questiona. E responde que nem sempre, dá exemplos, fala que problemas desse tipo ocorrem tanto na tradução intersemiótica, quanto em traduções interlinguísticas e infralinguísticas. E conclui que a tarefa de produzir uma teoria da tradução, tanto uma limitada ou específica, quanto uma extensa ou geral, exclusivamente voltada para sistemas linguísticos, está fadada ao fracasso. E então, apresenta argumentos para mostrar que uma teoria geral da tradução não é possível. São eles: primeiro, que a tradução é um fenômeno textual e sua matéria prima é a substância, aqui entendida como conteúdo, que lhe é específica, e não a forma de expressão; segundo, a tradução é um fenômeno individual, como o estilo, do qual se possa fazer talvez descrições semióticas, mas não uma teoria integral; e terceiro, a tradução, devido a questão cultural, é teorizável localmente mas não globalmente, ou seja, "regras podem ser generalizadas, mas apenas entre um conjunto de manifestações que apresentam fenômenos comparáveis entre si". 


\section{0 fenômeno Semiótico da Tradução em Omar Calabrese: Uma Resenha}

\section{A Partir de Jackobson: Algumas Dúvidas}

Revisitando Roman Jackobson (1963), Omar Calabrese retoma suas observações sobre tradução, bem como a classificação por aquele proposta: tradução infralinguística, dentro da mesma língua; tradução interlinguística, de uma língua natural para outra; e tradução intersemiótica, entre sistemas semióticos distintos. Afirma que essa tipologia não parece funcionar através de princípios consistentes e bem definidos, pois é baseada em dois pressupostos: um que não foi ainda demonstrado e outro incorreto.

0 primeiro pressuposto é o de que a tradução só pode ser generalizada se considerarmos que todos os sistemas semióticos são totalmente equivalentes, ao menos em algum nível e, deste modo, perfeitamente comparáveis. Comenta Omar Calabrese: "isto não está completamente certo, pelo menos no estado atual de conhecimento." Levantando o questionamento sobre o ser das diversas substâncias, pintura, por exemplo, se ela pode ser considerada linguagem ou não, afirma que "para que se possa falar de uma linguagem duas precondições são necessárias - uma lista de unidades mínimas que constitua seu eixo paradigmático e uma lista de regras de combinação daquela unidade que forme seu eixo sintagmático."

0 segundo pressuposto é que se imagina ser possível uma análise semiótica sem considerar ou sem se conhecer completamente o sistema. A lógica fundamental dessa posição é que as linguagens podem ser tratadas do ponto de vista de suas equivalências, especialmente nos textos em que certas condições são seus próprios sistemas. Após apresentar diversos exemplos, o autor afirma que o pressuposto fundamental da tradução é a relação entre textos e não entre sistemas. E que o que conta é o fato de que um processo é transformado em outro, estabelecendo-se preventivamente as equivalências, considerando as questões sistêmicas apenas em determinados níveis, específicos daqueles textos em questão.

\section{A Tradução: Uma Transferência de Conteúdo Entre Processos}

Calabrese lembra que existe uma tradição semiótica, "considerada generativa, de implantação comparativista e estruturalista" para a qual o problema das linguagens específicas não existe. Ao menos no sentido que é negada a possibilidade de existência de sistemas autônomos na colocação da relação entre Plano de Expressão e Plano de Conteúdo, dimensões do texto segundo esquema proposto por L. Hjelmslev (1943), que substituiu com vantagens a conhecida dualidade textual saussureana "significante e significado".

Eis então que o autor apresenta, mesmo não se propondo a conceituar, um conceito de tradução: o Plano de Conteúdo é um só, enquanto há diversas maneiras de se formar 0 Plano da Expressão, de acordo com a matéria utilizada por uma substância, ou seja, a Santa Ceia tem um Plano de Conteúdo que pode ter como Plano de Expressão diferentes substâncias como a pintura, o cinema ou o texto verbal. Em contrapartida, nessa 


\section{0 fenômeno Semiótico da Tradução em Omar Calabrese: Uma Resenha}

operação o próprio Plano do Conteúdo, a cada substância assumida é re-formulado, em qualquer medida, mesmo que seu esquema geral permaneça. Em outras palavras, sempre segundo Calabrese, a tradução poderia ser definida como a transformação de uma mesma manifestação discursiva - entendida como temas e figuras organizados por regras de enunciação - de uma substância de expressão a outra. Porém, ele alerta que tal transformação "não é automática nem indolor", pois toda forma de expressão possui vínculos: de natureza material, pois não se pode reproduzir o mesmo efeito sensorial; de natureza sintática, pois não se pode reproduzir a mesma organização; e de natureza semântica, pois não se pode reproduzir segmentações "lexicais" do conteúdo a partir de segmentações "lexicais" de expressão.

0 fator essencial de qualquer tradução é a vontade de transferir um determinado conteúdo, manifestado em um determinado Plano de Expressão, para outra expressão ou substância. Isto terá como limitação o vínculo formal da nova expressão e as transferências decididas pelo agente tradutor. Porém quando se fala de vínculo à uma determinada linguagem, também se fala de aspectos sistêmicos, que não são globais, mas sim específicos. 0 exemplo citado por Calabrese é o de uma das traduções de Picasso do quadro "As meninas" de Velázquez, em que Picasso utiliza somente as cores preta e branca, transformando o sistema policromático de Velázquez em um sistema monocromático. "Esse novo texto, e somente ele, segue uma regra formal que o diferencia do texto original", afirma Calabrese.

Entretanto, temos que ficar de acordo com o autor quando diz que o verdadeiro problema na análise da tradução intersemiótica é conseguir identificar e separar quais são as regras de transferência de conteúdo entre os processos para, a partir dali, operar no sentido de distinguir os casos que se pode chamar de tradução dos que não se pode.

\section{A Tradução Como Fenômeno Estilístico}

Outro enfoque adotado por Calabrese para discutir as inúmeras dimensões do problema da tradução é considerar tal processo como próximo - mas não idêntico - ao estilo. Para tanto, este autor alude aos estudos sobre estilo de Charles Bally (1947) e destaca o aspecto individual de cada texto, que se deve ao peculiar uso da língua, que caracteriza o autor, a obra, um grupo, uma tendência, uma corrente ou uma episteme. Fala então Calabrese de uma "tipologia estilística". Vale a pena transcrever essa tipologia, de acordo com o autor:

- manutenção do estilo - transferência de conteúdo com reproposição de figuras; exemplo: a llíada de Monti;

- perda do estilo - transferência de conteúdo com perda de suas figuras; exemplo: Beowulf na versão escolástica;

- adequação do estilo - transferência de conteúdo mudando suas figuras para um estilo pré-definido; exemplo: a versão rock do Bolero de Ravel;

- troca de estilo - transferência de conteúdo com mudança das figuras para um novo 


\section{0 fenômeno Semiótico da Tradução em Omar Calabrese: Uma Resenha}

estilo; exemplo: As meninas de Picasso;

- permanência do estilo - somente transferir as figuras sem transferência de conteúdo algum; exemplo: homofonias entre o inglês e o dialeto napolitano nas músicas dos Beatles executadas pelo grupo Shampoo.

Após a apresentação da tipologia, Calabrese então questiona se, ao considerar a tradução como fato estilístico, se ela ainda poderia ser considerada fenômeno semiótico, já que a estilística ocupa-se do uso individual da língua, ao contrário da semiótica. Citando outros autores que se posicionam a favor ou contra, Calabrese introduz mais uma vez a possibilidade de um texto ser o sistema de si mesmo, princípio já visto anteriormente. Defende, paralelamente uma semiótica dos processos: se estilo puder ser percebido como pertinente à tal semiótica, a mesma consideração pode valer para a tradução. Esta viria a se definir como "transferência de um conteúdo de um texto original a um texto de chegada, por meio de uma estrutura equivalente ao estilo."

\section{Tradução: Transformação x Interpretação}

Outro aspecto abordado no contexto do estudo do fenômeno da tradução por Calabrese é a interpretação, por conta da confusão que habitualmente é feita entre tradução e interpretação. E apela para diversos autores para afirmar que o debate continua acerca de a tradução não ser a construção de uma equivalência semântica de um texto, passado de um sistema semiótico a outro, mas ser, ao invés disso, interpretação. Admite, a seguir, que os vocábulos "tradutor" e "intérprete" são quase sinônimos, em italiano; e que ao se traduzir não se pode deixar de fazer algum tipo de interpretação. Mas afiança que se seguirmos esse pensamento podemos ir contra raciocínios menos evidentes. Isto porque se interpretar um texto é "avaliar e decifrar o conteúdo de uma expressão e manifestá-lo de outro modo"; e aí faremos juízos de valor cognitivos, históricos, sociológicos, antropológicos, ou seja, não pertinentes ao campo da semiótica. Mas se, ao contrário, atribui-se a interpretar o sentido técnico de "substituir uma expressão por outra que seja interpretante" , então insere-se no conceito de tradução noções heterogêneas. Neste sentido, a definição, a sinonímia, a paráfrase, a metáfora, a metonímia e a alegoria, entre outras figuras de linguagem, seriam traduções, afirma ele.

Vai mais além o autor quando acrescenta: "toda a semiologia seria uma gigantesca e ilimitada operação tradutiva". Após a hipérbole, afirma que isto não seria exatamente um absurdo, uma vez que a semiótica se ocupa da compreensão dos textos e das trocas cognitivas entre seus leitores. Mas conclui dizendo a respeito deste ponto que tal teoria da tradução seria muito abrangente e, em assim sendo, teria pouca utilidade. Por outro lado, lembra que entender a tradução como "transferência de sentido de um texto para outro", pode pressupor, por exemplo, que um dicionário inglês-italiano é a tradução da língua inglesa em italiano. Mas sabemos que não é: o dicionário é apenas 0 instrumento por excelência passível de possibilitar a seleção de equivalências lexicais entre as duas línguas. 


\section{0 fenômeno Semiótico da Tradução em Omar Calabrese: Uma Resenha}

Conclui Calabrese esta seção dizendo que, em síntese, a tradução envolve a suposição básica de que um texto pode ser convertido em outro texto, levando em conta: que essa conversão seja feita por um agente determinado; que este agente faça a transformação a partir de motivações e objetivos específicos; que ele tenha a competência necessária para desenvolver tal operação; que o resultado final tenha uma "sanção".

\section{A Tradução Como Fenômeno de Transformação, ou Melhor, Narra- tivo}

A narratividade é outro parâmetro para a análise do conceito de tradução. Segundo proposto no item anterior, em toda tradução há uma metanarração: é o percurso que consiste na transformação de um texto de origem em um texto de chegada e que inicia com um agente que opera a partir de uma motivação, por meio de uma competência, fazendo atos específicos e que é reconhecido como uma solução boa ou ruim, ao final da operação.

Calabrese defende a ideia de que em qualquer tradução existem traços desta metanarração. E diferencia uma tradução verbum pro verbo, isto é, fiel, de uma tradução autônoma: na primeira, há o nome do tradutor, do título, a língua de origem, critérios usados na tradução, além de notas de tradutor que explicam algumas escolhas necessárias; no segundo caso, no texto autônomo, usa-se termos como "livremente tratado por" ou "baseado em". Nestas informações encontra-se a narrativa da transformação de um texto em outro.

A seguir, Calabrese apresenta a relação das quatro fases da narração, que funciona como uma espécie de roteiro tanto para a tradução quanto para a análise de textos:

- manipulação: um destinador manipula um destinatário, levando-o a fazer a ação de traduzir, pelos modos do querer e do dever. Este destinatário se transforma de sujeito de estado ao sujeito do fazer e pressupõe a ação. 0 papel de manipulador pode ser assumido por diversos sujeitos envolvidos na ação: o público que consumirá a tradução; o editor, que a publicará; o próprio tradutor, no caso de se sentir estimulado a fazê-la. Por outro lado, o manipulado, ou seja, o destinador, será sempre o tradutor.

- competência: o sujeito antes da ação deve ter competência para executá-la, o que, no caso da tradução, seria o conhecimento de ambas as línguas ou de ambas as substâncias, além de outras específicas.

- performance: é o desempenho do sujeito ao executar a ação, resolvendo impasses, geralmente ligados a particularidades de uma ou outra língua, sendo que muitas dessas dificuldades ficam registradas nas notas do tradutor.

- sanção: o sujeito manipulado, o tradutor, nesta etapa é reconhecido e julgado pelo manipulador por ter finalizado a ação, a partir de determinados critérios. 


\section{0 fenômeno Semiótico da Tradução em Omar Calabrese: Uma Resenha}

Após colocar os sujeitos da manifestação em relação por meio das etapas do processo gerativo de sentido, Calabrese apresenta o também clássico esquema da narrativa bási$\mathrm{Ca}$, qual seja, $\mathrm{S}$ disjunto do $\mathrm{O}$-> $\mathrm{S}$ conjunto de 0 , onde $\mathrm{S}$ é o sujeito tradutor, separado de 0 , objeto de valor, neste caso, um texto em outro idioma, que ele mesmo, $\mathrm{S}$ se propõe a transformar, em conjunção com o objeto 0 , que é o texto traduzido. Assim, o texto final da tradução e a narração desta ação, já manifestam as operações realizadas entre os dois textos. Conclui Calabrese: "importante é que seja indicada a comparação entre os dois textos e dois autores e que dali derive a construção da equivalência entre os dois processos."

\section{Tipologia Transformativa e o Percurso Gerativo}

Nesta seção Calabrese põe-se a analisar a natureza dessa operação e sua tipologia, não sem antes propor um parêntese para tratar do problema sob a ótica dos motivos iconográficos nas obras figurativas. Três autores se ocupam deste assunto. Para tanto, cita Aby Warburg, Rudolf Wittkover, aluno de Warburg e Erwin Panofsky. Para Warburg, o fato que uma figura feminina, nua, deitada com a cabeça apoiada numa das mãos, seja encontrada em estátuas orientais, estátuas gregas de ninfas, em Giorgione, Tiziano, Velazquez e em alguma propaganda de cruzeiro do século XIX, não é apenas uma citação, mas também uma tradução. Isto porque existem conteúdos que se mantêm os mesmos, passados de uma cultura para outra. Referindo-se a Wittkover, diz que ele foi além e chamou o fenômeno de "transmigração dos símbolos". E quanto a Panofsky, Calabrese lembra sua afirmativa, de que toda arte figurativa ocidental, seja medieval ou moderna, traduz visualmente, de algum modo, um texto verbal.

Para Calabrese os exemplos iconográficos por si só não constituem tradução, a não ser que seja procedido o confronto de identidade entre textos e autores. Analisando as postulações dos iconólogos, Calabrese reconhece que eles também têm a intenção da passagem textual de uma semiótica a outra como uma transferência de conteúdo, através de uma mudança de expressões, a qual pode ser feita em diferentes níveis. Pode-se fazer migrar um motivo, no nível da configuração discursiva, como as folhas de louro que envolvem em uma imagem um atleta vitorioso e, em outra, um poeta. ou a transferência pode ser de um tema e então a estrutura discursiva manifesta-se em uma sequencia narrativa, quando por exemplo, uma mulher e uma criança quaisquer tornam-se a Madona e o Menino. Haveria ainda a estrutura narrativa complexa e Calabrese traz como exemplo Uma Anunciação baseada no Evangelho de Marcos e outra que segue os Evangelhos apócrifos.

Afirma que a maioria das traduções dão-se no nível discursivo e por este motivo as variações sintáticas dão-se neste nível. Entretanto, admite que a mesma coisa pode acontecer também no nível semio-narrativo e no profundo. Desta vez o exemplo é o filme de Jean-Luc Codard, "Je vous salue Marie, no qual a história de Maria é radicalmente mudada. Calabrese termina essa seção afirmando que mesmo usando exemplos "extremos" não quer dizer que qualquer tipo de texto o qual se refira a outro possa ser considerado uma tradução, mesmo havendo alguns efeitos de sentido que caracterizem 


\title{
0 fenômeno Semiótico da Tradução em Omar Calabrese: Uma Resenha
}

uma transmigração.

\section{Graus de Equivalência dos Efeitos de Sentido}

Calabrese defende a singularidade de cada tradução, justificando pelo fato de ser processo, o que ao menos aponta para uma singularidade. E logo, explicitando a questão da autoria, que nunca deixa de ser subjacente, apresenta uma pergunta: sob quais condições a identidade do autor é realmente mantida? Dizendo que existem diferentes graus de equivalência na transferência do sentido de um texto para outro, afirma que esses graus dependem de dois fatores: da escolha dos efeitos transferidos; das variações que o tradutor cria para ser reconhecido como autor.

Lembra que os aspectos relacionados ao primeiro fator já foram os apresentados na seção 5, manutenção, adequação, troca e perda de estilo; acrescenta que estes tipos dependem da natureza do estilo do texto de origem, a ser traduzido. Seu exemplo é elucidativo: quando um autor brinca com a idioma e fica impossivel traduzi-lo na íntegra e literalmente, o tradutor precisa se decidir entre perder todo o efeito expressivo ou adequá-lo de outro modo. E continua "como traduzir o título de uma poesia de Rimbaud chamada "J'est un altre"? Literalmente "Eu é um outro", não traduz a ambiguidade. MeIhor acrescentar uma vírgula "Eu, é um outro", porém perde-se o ritmo transformando um verso rápido em uma pausa. Além da possível homofonia de "J'est" e "J'ai" ("eu sou" e "eu tenho")." Segundo Calabrese, aí a identidade se perde.

A seguir, Calabrese toma um outro exemplo, que ele mesmo considera difícil; trata-se da tradução visual do Evangelho de Marcos, na qual o anjo faz o anúncio a Maria de que ela será a mãe do Senhor: uma obra de Fra Angélico, que hoje se encontra no Museu do Prado, uma das muitas versões que o beato pintou desta cena.

Vale a pena acompanhar o relato pelas palavras do próprio Calabrese:

\begin{abstract}
a passagem contém, em ordem cronológica, cinco momentos previstos pela retórica da conversação entre o humano e o divino (surpresa, saudação, humilhação, obediência, glorificação). 0 que faz Fra Angélico na Anunciação do Prado? Coloca todos os cinco momentos na tela, ao mesmo tempo: a mão esquerda para frente mostra a saudação à chegada do anjo, a direita vira-se para o peito como em surpresa, os olhos baixos demonstram humilhação, a cabeça inclinada significa a obediência, a vestimenta vermelha e azul comunica a glorificação. Perdeu-se a trama, mas o instantâneo diz igualmente tudo, e tradução é quase literal.
\end{abstract}

Resumindo seu pensamento acerca deste aspecto, qualquer que seja a substância de expressão comparada com a substância original, pode-se dizer que existem efeitos de sentido que podem ser mantidos e outros que podem ser mudados ou eliminados, mas o que importa é a seleção do que se deseja fazer, bem como o grau de identidade que se quer manter entre as duas substâncias. Em termos de presença, do autor e do tradutor, no texto traduzido, cujas identidades podem ser anuladas ou exaltadas, Calabrese 


\section{0 fenômeno Semiótico da Tradução em Omar Calabrese: Uma Resenha}

propõe o seguinte esquema:

1. autor > tradutor

2. autor $=$ tradutor

3. autor $<$ tradutor

Como os sinais gráficos indicam, no primeiro caso, o tradutor se anula para dar destaque ao autor. No segundo, os dois assumem identidades próprias, sem cancelar a presença um do outro. E no terceiro, o tradutor vira autor, pois assume identidade própria; e 0 autor fica subordinado ao tradutor. Nessas três categorias há a busca de um grau de equivalência entre fonte e alvo, ou seja, entre o texto original e o texto traduzido, 0 que mudará de acordo com o quanto se deseja manter da identidade autoral dos dois textos.

\section{Cortes na Tradução: Molecular Versus Molar}

Na seção 10 do seu texto, Calabrese retoma sua hipótese geral, a de que se pode conceder o nome de tradução a qualquer texto no qual se coloque o objetivo de reproduzir um outro texto, desde que em sentido forçosamente parcial. Acrescenta ainda outras condições para que o texto seja considerado tradução: ele deve ser individualizável e identificável; e o objetivo da parcialidade deve ser declarado. Esta é a introdução para se buscar entender como e porquê o mecanismo ocorre da parcialidade. Calabrese parte do pressuposto que o tradutor define preliminarmente a maneira de abordar o texto de origem, escolhendo o que ele chama de "corte da decodificação", pois para ele existem dois tipos extremos para traduzir um texto: a tradução molecular e a tradução molar.

A tradução na qual seu interventor opta por seguir termo a termo a construção inicial, de origem, quase linear, seja ele verbal, visual ou outro, mesmo não tendo a característica linear, "a medida pré-escolhida é, por exemplo, aquela lexical ou frasal." É o que se costuma chamar de "traduzir ao pé da letra", ou seja, palavra por palavra. É o que chama de tradução molecular.

Para nosso intento que se preocupa mais com a relação entre linguagens distintas do que entre línguas naturais, nos damos conta que o autor admite esse tipo de tradução fragmentada, "ao pé da letra" também entre semióticas distintas, entre linguagens diferentes, como entre a linguagem verbal e visual: "o exemplo mais clamoroso foi estudado por Louis Marin (1978) a propósito de Poussin, o qual envia um auto-retrato ao amigo Philippe de Chantélou com uma carta de acompanhamento e descrição, na qual afirma: "leia a carta e olhe o quadro, e diga-me se convergem." A categoria apresentada como em oposição à tradução molecular - com ela contrastando - é a molar. Ao contrário das partes isoladas, leva-se em conta o todo, ou seja, em compreender o texto, em um primeiro momento, "como um sistema, para então segmentá-lo em diferentes categorias, escolhendo a medida que mais convém à operação tradutiva desejada." 


\section{0 fenômeno Semiótico da Tradução em Omar Calabrese: Uma Resenha}

A tradução denominada molecular tenta ser mais fiel ao conteúdo, reproduzindo o sentido amplo, mas nem por isso menos profundo, de um texto. 0 dado comunicacional, semiótico a se lamentar, diante dessa opção, é a impossibilidade de se manter valores característicos do texto-fonte, ou testo di partenza, como os estéticos, estilísticos e mesmo os consideráveis passionais, "mesmo quando a tradução é aparentemente muito correta.", como destaca Calabrese. Não é inesperado que o texto molar ultrapasse o texto de origem, o texto-fonte, em diversos aspectos, uns menos relevantes, como o detalhamento, o acréscimo de elementos; e outros, valores mais consistentes, como os de ordem estética, bem como a tímica, categoria semiótica que articula a euforia e a disforia na construção de textos quaisquer, verbais, visuais, sonoros, fílmicos ou outros.

Para melhor compreender, de um modo conclusivo, como um panorama desse aspecto específico mas fundamental para os processos de criação, usando a oposição semântica e operacional proposta por Calabrase, qual seja, molecular e molar, torna-se necessário atentar às palavras do próprio semioticista: "dificilmente a tradução de um texto estético poderá ser molecular porque deverá restituir ao texto-alvo as invenções que são identificáveis justamente reconhecendo no texto seu caráter individual de sistema de si mesmo." E continua, afirmando que cada texto poético é um sistema de si mesmo; pois, de outra forma, sua auto-reflexidade (aquela que Jakobson [1963] chama de função estética, e que consiste de um apontar na referência a si mesmo) se perderia. Cada texto poético, em suma, impõe uma análise por categoria e portanto também uma tradução por categoria. E esta última afirmativa poderia ser fonte de muitas discussões e exemplificações, principalmente se trouxer para o campo de semióticas ou linguagens distintas entre si, ou seja, cujos modos de expressão se estruturam diferenciadamente, isto é, para o campo dos textos estéticos.

\section{A Tradução Como Trabalho Categorial}

Chegando às últimas considerações em seu texto sobre a tradução, lembrando que ele consiste na introdução de uma coletânea de artigos que contém análises específicas sobre determinados objetos de estudo, os mais variados, Calabrese reitera o que parece ser o fruto de suas reflexões e práticas, ou seja, a defesa da tradução molar. Ao menos, é esta que ele afirma ser aquela que mais lhe interessa.

Por quê? Ora, não se trata, como a tradução molecular, de uma repetição quase automatizada de sinônimos dicionarescos. Há a necessidade de um conhecimento de área, ou seja, dos princípios que regem a linguagem, não como uma mera forma de expressão coloquial, mas aqueles pertinentes a dois campos específicos do saber constituído e sistematizado, qual seja, a semiótica em primeiro lugar; e as características próprias do modo de expressão estética ao qual pertence o texto em vias de ser traduzido, uma análise categorial. Portanto, para Calabrese, a tradução molar implica uma análise preliminar do texto-fonte, ou do testo di partenza, na sua globalidade; e depois, no seu desenvolvimento, para então se proceder à "reprodução implícita daquela mesma análise no texto-alvo." 


\title{
0 fenômeno Semiótico da Tradução em Omar Calabrese: Uma Resenha
}

Aqui então ele retoma "a utilidade heurística de um conceito ainda pouco desenvolvido: aquele de semisimbólico". Lembrando os desenvolvimentos anteriores da semiótica, Calabrese traz para a discussão os dois modos clássicos de considerar as semióticas, ou as linguagens, quais sejam, o simbólico e o semiótico, acrescentando um terceiro modo, o semisimbólico. De acordo com ele, o simbólico e o semiótico “contrapõem duas maneiras diferentes de entender as relações entre Expressão e Conteúdo segundo os cânones do isomorfismo e da conformidade." E explicita dizendo que o modo simbólico vê os dois planos como isomorfos (iguais grandezas) e conformes (igual unidade): por exemplo, o sistema das luzes de um semáforo, no qual aparecem três unidades

de expressão = /amarelo/, /verde/ e /vermelho/ - e três de conteúdo - "atenção", "parada" e "via liberada". 0 modo semiótico os vê, ao contrário, como não-isomorfos (diferentes grandezas) e não-conformes (diferentes unidades): por exemplo, a linguagem natural, na qual um vocábulo como /cão/ é decomponível em modo deveras diferente em unidades expressivas e de conteúdo.

E continua seus esclarecimentos acerca do que diferencia o modo semisimbólico dos dois modos anteriormente explicitados: o modo semisimbólico é não isomorfo, mas é conforme. Ou seja, o modo semisimbólico não se prende à unidades, mas sim, categorias reconhecidas em um texto, categorias essas que não têm a mesma grandeza nos dois planos, o Plano de Expressão e o Plano de Conteúdo, mas instauram um sistema de oposição entre unidades idênticas, mas não iguais. Eis o exemplo apresentado por Calabrese:

\begin{abstract}
No quadro Vence os Brancos com a Cunha Vermelha de El Lissitzky, reconheço duas unidades geométricas (/cunha/, /cerco/), duas cromáticas (/vermelho/, /branco/), duas topológicas (/fechado/, /aberto/) que não têm a mesma condição daquelas de conteúdo ("os vermelhos", "os brancos"), ("ataque", "defesa"), ("inserção", "rachadura"), mas que são entre si perfeitamente conformes. Não conheço o sistema da pintura, nem o da pintura abstrata, mas reconheço a semiótica e reconheço o sistema daquela obra individual, posto da mesma lei.
\end{abstract}

Portanto, na tradução molar o novo autor faz o que Calabrese denomina de análise categorial do texto original e se dedica a reportar-se, conscientemente, em parte, ao texto original, de acordo com a estratégia e os objetivos de transmutação selecionados e adotados para a preservação do texto-alvo, ou o texto traduzido. Ainda - e sempre de acordo com Calabrese, a tradução molar pode ser considerada como uma tradução inovadora, pois foca a atenção nos traços particulares identitários do texto original, isto é, aqueles que constituem, de fato, sua natureza estética e original, ou seja, singular.

As diferenças são evidentes, mas não estruturais, nem relacionadas às singularidades que, provavelmente, tornaram o texto de origem digno objeto de tradução para outras línguas ou linguagens. Calabrese diz que este tipo de tradução, molar, movimenta e desafia o texto de origem, até o ponto mesmo de propor uma nova singularidade. E nos mostra, como exemplo, um fato corriqueiro: "é por isto que, por outro lado, amamos certas traduções que não estão certas de jeito nenhum, mas infinitamente melhores do que outras que se achatam no modelo, mas não se the colhem a natureza." Vai mais 


\title{
0 fenômeno Semiótico da Tradução em Omar Calabrese: Uma Resenha
}

além, não só exemplificando com um tipo de sensação que com frequência pode nos assolar, mas com uma situação concreta:

\begin{abstract}
é por isso que pode acontecer que a tradução cinematográfica de uma obra literária (por exemplo: Nosferatu de Herzog trazido ao Drácula de Stocker) nos apaixonam mais que outra tradução literária, ou que certas descrições ecfrásticas de Diderot sejam até mais belas que os quadros de Vernet expostos nos salões parisienses. 0 fato é que uma versão estética de um texto estético termina com o não limitar-se à pura transmigração de figuras discursivas de um texto ao outro, mas adiciona qualquer coisa de mais abstrato e valioso (...).
\end{abstract}

0 que se deduz é que tradução é, além de um fazer complexo, passível de adoção de estilos distintos e que nenhuma delas será perfeita. Nela acontece a mesma imperfeição prevista por Greimas (1987), transformada em programa de ação tradutiva capaz de produzir efeitos não apenas estéticos, mas também poéticos. Por último, neste ítem Calabrese chama a atenção para o fato de que, no plano teórico, o pano de fundo analítico destaca e discute, se não, resolver, um problema que tem sido marginal para qualquer semiótica, qual seja, o da singularidade e, subjacentemente, da unidade da obra de arte.

\section{Conclusão Antiderridiana: Tudo É (Imperfeitamente) Traduzivel}

Calabrese se apega, ao longo da sua argumentação, à possibilidade da tradução, embora reiterando que ela sempre será imperfeita. Então, lembra Derrida (sem fonte citada) e sua premissa da impossibilidade de tradução, afirmando que "tudo é (imperfeitamente) traduzível, e de qualquer semiótica a qualquer outra semiótica". Entretanto, ele apresenta a necessidade de seguir dois princípios: aquele da posição explícita da equivalência entre dois textos e dois autores, que implica um programa analítico de seleção das categorias e das pertinências desejadas. E aquele do pressuposto da autonomia do texto (uma substância), ou um conteúdo, que se tornará outro sistema (uma forma), ou uma expressão.

E deixemos Omar Calabrese concluir com palavras mais próximas nas quais o português pode se aproximar do italiano, palavras, talvez, irrepetíveis: "os valores irrepetíveis da obra são salvos, mas não ao preço de um geral irracionalismo crítico, mas sim salvando também a benevolência dos procedimentos semióticos da análise."

\section{Peroração}

Embora conscientes das transgressões inerentes ao fenômeno no qual consiste a tradução, mesmo considerando-a uma tradução molar, buscamos ampliar a discussão, trazendo para o campo de outras linguagens estéticas, problemas por vezes restritos 


\section{O fenômeno Semiótico da Tradução em Omar Calabrese: \\ Uma Resenha}

ao campo exclusivo do verbal, num momento histórico no qual mais se miscigenam os modos de expressão, tanto por via tecnológica quanto presencial.

Para terminar, vale a pena recuperar o título que Omar Calabrese deu para seu artigo, "0 estranho caso da equivalência imperfeita", no qual sintetiza sua posição e antecipa o desfecho do texto. Entretanto, é no subtítulo que a identidade do autor se manifesta: "modestas observações sobre a tradução intersemiótica". Especialmente em relação ao adjetivo anteposto ao substantivo "observações", qual seja, "modestas". Ele atesta 0 modo cuidadoso com que o autor apresenta suas postulações. 


\section{O fenômeno Semiótico da Tradução em Omar Calabrese: \\ Uma Resenha}

\section{Referências}

> BAKHTIN, M. “Une surce de l'intextextualité? La dialogisme”. In: RAHU, Sophie. L'Intertextualité. Paris: Flammarion, 2002.

> BALLY, Ch. Traité de stylistique française. Paris: Georg, 1947.

> CALABRESE, 0. "Lo strano caso dell'equivalenza imperfetta (modeste osservazioni sulla traduzione intersemiótica)". In: CALABRESE, 0. Fra parola e imagine: metodologie ed esempi di analisi. Milano: Editora Mondadori Universitária de Milano, 2008.

$>$ GREIMAS, A. J. ¿̨ COURTÉS, J. Diccionnaire raisonné de la théorie de la langage. Paris: Hachette, 1979.

> GREIMAS, A. J. De l'imperfection. Paris: Fanlac, 1987.

$>$ HJELMSLEV, L. Omkring sproegtheoriens grundlaeggelse. Kobnhavn: Ejnar Munksgaadr, 1943.

> JAKOBSON, R. Essais de linguistique générale. Paris, Seuil, 1963.

> MARIN, L. Détruire la peinture. Paris: Galilée, 1978.

Júlia Pelachini Farias

julia.p.farias@gmail.com

Sandra Regina Ramalho e Oliveira

ramalho@floripa.com.br 